\title{
FLOWERS IN THE GARDEN: A GLANCE ON MULTILINGUALISM IN MALAYSIA
}

\author{
Ain Nadzimah Abdullah*, Rosli Talif*, and Jariah Mohd. Jan \\ *Universiti Putra Malaysia and University Malaya
}

\begin{abstract}
This paper examines the recent changes to the Malaysian linguistic situation that had grave implications for the modifying of the language use in education. It discusses the status of English in pre-and early independent years and how language was revolutionised and replaced due to the widespread communicative use of Bahasa Melayu. Issues that underlie teacher apprehension as a result of the policy change and their language preferences are also highlighted. Investigating and understanding their apprehensions will help policy makers understand the impinging forces that have an impact on any policy innovation.
\end{abstract}

\section{KEY WORDS: MULTILINGUALISM, MALAYSIAN LINGUISTIC SITUATION, LANGUAGE USE, EDUCATION}

\section{Introduction}

Monolingualism is retreating in favor of multilingualism all over the world. In Malaysia, the public school system essentially provides language contact initially through three major spoken local languages - Malay, Chinese, and Tamil. At the elementary level, children have a choice of attending national schools or national-type schools. National schools are those that follow a curriculum that is conducted mainly in the national language, which is Malay. On the other hand, the national-type schools make use of vernacular languages (Mandarin and Tamil) as the main medium of instruction. However, this division ceases to apply at the secondary level where all subjects are taught in the national language. Chinese secondary schools are privately run and students enrolled in these schools can also opt to take the public national examinations. There are no Tamil secondary schools in Malaysia.

The current Malaysian linguistic scenario has come about due to several reasons. Among them, the most exerting ones were the pre-independence dominance by foreign powers (in particular, the British) and post-independence nationalistic fervor that led to a concerted effort to replace the foreign dominant language - English -with an indigenous language.

\section{The status of English in pre- and early independent Malaysia}

Prior to Malaysia's independence in 1957, the British had brought along the English language which soon became the main language for trade, government matters and education. An education in 
English was often seen as a value-added experience which provided a person with a better future. Asmah (2003) noted that, "a certificate from the English school promised jobs in the government and in the private sector, and most of all it opened the path to higher education." In contrast, the vernacular schools only "produced literate farmers, carpenters and small time shopkeepers".

Malaysia gained its independence in 1957, and with it, language contact took on a different interpretation. Post-independence nationalistic fervor saw the need to identify one of the local languages to be the national language to replace English which naturally had negative colonial associations. In the words of Asmah (2003, p. 67), the Malay language was "the best choice to fulfill this function", one of the reasons being its widespread communicative use across ethnic groups.

With the implementation of the 1963 National Language Act, the medium of instruction in schools was changed from that of English to the Malay language. However, the vernacular language contact in schools was also given due recognition. The Chinese and the Tamil primary schools were allowed to continue the use of their respective ethnic languages as the language of instruction. Thereafter, there would be one common public school system at the secondary level. This concession appeased the ethnic minorities (Indians and Chinese) who essentially felt the need to safeguard their identities through mother tongue preservation. With this move, the language contact in schools was formalized. However, English remained very much a language widely used for interaction especially in the urban areas. Asmah (1994) recognizes this situation as a consequence of nationalism and 'nationism'. While nationalism attends to national aspiration of a united race, "nationism, supported by proficiency in the English language is essential in Malaysia's rise to become a developing and industrial nation and to take its place in internationalism" (ibid.: 71).

\section{'Language policy advance' in independent Malaysia}

In the years since 1970, in a dramatic turn-about, the Government adopted English for teaching Mathematics and Science to Primary 1 and Secondary 1 students, who would continue to receive instruction for the subjects in English until they complete their secondary education in the national schools. This change is unprecedented and viewed as drastic by many. Much talk has gone on to arrest the decline of English language proficiency, but the new policy advance was hardly envisioned by most. As a result of the 'sudden' advance of the new policy, many were caught by surprise. At the initial stage, various opinions were expressed - some in support of the policy, many opposed it, and a few offered alternative options. Despite opposition from some quarters and the seeming contravention, the new language policy has not been challenged in a court of law, and is thus deemed a fait accompli.

The bilingual policy innovation was ushered on the initiative, or rather political will, of the then Prime Minister, now Tun Dr. Mahathir Mohamad. The timing was provided by the growing unemployment rate among graduates which was attributed to their selected fields of studies and their poor proficiency in English. He asserted that Malaysians must be competent in the English language if they were to compete in the international market. The call for a change was a calculated maneuver. After 48 years of independence, the position of Malay as the national language is apparently secure. This translates into a lesser political risk in wanting to re-emphasize the mastery of English. The Ministry of Education subsequently announced the change that Mathematics and Science would be taught in English with effect of 2003 and implemented beginning from the first year of primary and secondary schooling (New Straits Times, 12 May 2002.). 
What then is the driving force, other than the issue of graduate unemployment that could affect such a radical change or advance? One well-touted reason is that the Malaysian Government, or at least Dr. Mahathir, was skeptical of Malay as being able to keep apace with the rapid development of knowledge, especially in the fields of science and technology. It was strongly feared that the goal of becoming a developed nation with a competitive knowledge-based economy and a world-class work force, would be compromised if a linguistic advantage is not evident.

Dewan Bahasa dan Pustaka (the national body entrusted with the task of propagating and developing the national language, i.e. Malay), and individual writers and translators, have contributed enormously in expanding materials in the national language. However, the evolution of new fields of knowledge has undergone a fast-paced revolutionary change. The daunting task of having to keep abreast with rapid current changes and the need to publish in Malay has resulted in an increasingly widening gap of availability in terms of translated materials. The avalanche of new information, new discoveries, and new knowledge constitute a kind of tsunami that is about to reach the shore and the time interval of every impact is becoming increasingly The Internet and computer technology connect people and engaged minds in a way never envisaged before, and, in most cases, in real or almost real time. Globalization and the use of English as a global language have come to stay. The nation could not remain in a state of denial deflating the importance of, or her dependence on English if she is to move forward and compete internationally. Given the social and linguistic climate, what then are the responses to a new policy change that invites repercussions with long range implications, especially for teachers in school?

Let us focus on recent changes to the Malaysian linguistic situation that had grave implications for the modifying of the language use in education situation. This arose from the change in the medium of instruction (i.e., from Malay to English) for the teaching of Mathematics and Science at all public Malaysian schools.

It is essential to examine the issues that underlie teacher apprehension as a result of the policy change. Changes to language planning and policy often invite controversy, and contentious public discussion, as it involves complex relationships between "cultural politics, curriculum, education practice and the modes of surveillance of the liberal state" Pennycook (1994, p.108). In language planning policy, a major influence may be ideology, though it may also be influenced by pragmatics. Often, in fact, there is a complementary relationship between both views, as language policy is usually a result of ideological and pragmatic (or instrumental) considerations. The differing emphasis and interpretations accorded to the functions could lead to language planning initiatives being misunderstood, misconstrued, or exploited for specific purposes. Studying the interrelationships between language, power and inequality are central to the understanding of language and society Tollefson (2002, p. 4).

In recent years, stated preference-based survey techniques - in particular, contingent valuation methods - have gained much popularity. In economics, these methods aim to trace the latent demand curve for goods, such as cultural heritage, which cannot be exchanged in traditional markets. Often, a contingent, hypothetical market is created where people are asked to state their willingness-to-pay (or willingness-to-accept) for a change in provision of the object of the valuation exercise. Recently, a book was dedicated to applications of contingent valuation methods to different sorts of cultural goods (Navrud \& Ready, 2002). These techniques show great potential for application in the realm of language preservation and valuation of the benefits of multilingualism. The stated preference-based survey method might be useful for our present purpose. 
Multilingualism can be regarded as an economic good and to this extent can be valued. The multilingual language situation presents an interesting supply and demand curve, where the supply, especially for a language of wider communication, is often determined by institutional constraints. The demand curve is related to the "status" of the language and the level of social cohesion of the community the language is being passed on to. A language is a crucial part of a specific community, shapes and builds its identity in the same way as its physical heritage does. Therefore, its existence needs to be valued and preserved as we do with the cultural and environmental heritage of a region. Using the stated preference questionnaire was potentially very useful to elicit the value of languages in Malaysia's multilingual situation.

To assess people's preferences, two main approaches can be used: one can look at the way people have behaved in the market, or look at the way people state they would behave in a future (hypothetical) market. The first class of methodologies goes under the name of revealed preferences techniques, while the second one is known as stated preferences methods. A change in the provision of a non-market commodity, such the provision of a specific learning program for an endangered language, has social and economic impacts and can be perceived either as a gain or as a loss by the affected population. Sometimes the loss is related to symbolic values that the public perceive as disregarded by the project, despite the overall improved conditions that would result from the policy advance.

\section{Language preferences: Some observations}

The stakeholders involved in the policy advance included teachers who are the main implementers and advocators of change. Investigating and understanding their apprehensions will help policy makers understand the impinging forces that have an impact on any policy innovation. The data for this source of information came from 72 primary and secondary mathematics and science teachers who took part in a questionnaire survey. Their age ranged from 22 to 47 years old.

There were a wide variety of responses among the teachers surveyed. Recurring themes were divided into positive/practical and negative (involving avoidance, insecurity or dislike). The negative outnumbered the positive by a factor of nearly 4 to 1 . The most frequent response was the non-usefulness of English for the learning of mathematics and science. Two related ideas - that English does not provide access to equality in the classroom, and to use English is not democratic were given in many formulations - 'we all need to make sacrifices - everyone understands it', 'if we keep English no one can say their language is the best'. Other recurring ideas included career prospects and personal improvement - 'I need English in my work ', and several cited the time taken to translate from one language to another. Some negative responses tended to be despairing - 'we have to learn English, it's no use to speak Malay all the time', or resigned - 'I have learned to settle with the present ruling.'

A substantial majority of teachers from all language groups did not prefer English as a language of instruction. The choice is most clearly expressed in response to the question which asked how they felt about the fact that the language of instruction for mathematics and science was English. 95\% of the total sample opted for 'very unhappy' and 'unhappy' rather than 'happy' or 'very happy'. Among a host of reasons given in response to the question was the fact that English is not the language most nearly understood by all (although to varying degrees). This provides a pressing practical consideration and cannot be ignored or overlooked by language planners and policy makers. 
Some teachers also expressed that they felt insecure having to teach mathematics and science using English. They stated that this fact is compounded even further when the text books, teaching modules and guidebooks are also in English. It is important to stress that a large majority of the teachers surveyed do not display a high level of proficiency in English. The completed questionnaires confirm that such teachers come from rural areas and tend to prefer to choose Malay as a language of instruction. Some teachers expressed concern and even resentment at having to teach mathematics and science in English. Others avoid using English in multi-lingual situations, since they perceive themselves to be disadvantaged.

\section{'Policy advance' and its apprehension by teachers}

First and foremost, there was a practical concern as to whether there are sufficient teachers fluent in English to teach these subjects within such a short notice of policy implementation. The issue of not sufficiently qualified teachers to teach English as a subject, especially in rural schools, is a recurrent one. However, the problem would now be compounded by an acute shortage of teachers capable of teaching Mathematics and Science in English. The key variables in any national development equation are human resources, natural resources, scientific knowledge, and technological know-how set in motion by national consciousness or nationalism. However, it is not sufficient to have an abundance of human and natural resources for development to take place. Available human resources must be transformed into knowledgeable, specialized or skilled manpower by an education or training process in order for them to be useful in the national development equation. In other words, of all the elements in the national development equation, human resources are the most important. This is evident from the fact that most African countries are very rich in natural resources, and yet are underdeveloped. Many Arab countries, with their enormous oil wealth, are nevertheless relatively underdeveloped as well.

Only people possessing knowledge and skills, acquired through education and training, can serve as agents of change, to convert raw materials (natural resources) to finished products for consumption in the national economy. If rapid access to knowledge (information) is to be guaranteed, then language should not constitute a barrier to information and knowledge, as lack thereof would negatively affect productivity. Once there is continuity between multilingual education and training, on the one hand, and language practice in the work place, or on the production floor, economic development could be expected to be triggered. It does seem that national development cannot occur in Malaysia unless an appropriate language policy, which includes the functional use of a national language, indigenous languages together with a language of wider communication, is integrated into the national development plan. Clearly, economic development is a central feature of national development, hence the link with language.

Secondly, the teachers also stated that introducing a multilingual context in schools introduced problems of a technical nature. The interpretation and translation services perform an essential task of mediation between the different languages, and without them the practice of institutional multilingualism would not be imaginable. However excellent they are, the linguistic services cannot solve all the problems created by the need for multilingualism, and it is inevitable that more or less serious difficulties will arise. Precision was cited as an important factor which could result in problems for the policy advance. The problems concerning precision were associated with several factors. The first problem cited involved untranslatability. Teachers felt that there may be some terms that cannot be translated from one language to another. The most immediate consequence of this is that it is not always possible to find the equivalent in one language of what the other 
expresses. The other technical problem cited concerned precision. Teachers associated this problem with regard to the quality of material written non-mother-tongue writers. They explained further that however well the writers manage to produce such material; there will be inevitable interference between languages in the vocabulary and syntax. The result of all this may be a low quality of the original texts and uncertainty over the real lexical intentions of the author. Another technical problem cited by the teachers was the element of speed. They claimed that working in different languages slows down the work, especially when written texts need to be translated. The need for a sufficient amount of time to translate documentation can sometimes clash with requests to have it available urgently, or may even become a pretext to stop the work. Finally, the last technical problem that was expressed concerned apprehension towards the deterioration of style. They claimed that if they were to use a different language from their own, they generally would not be able to express themselves to the best of their abilities.

Another important response which the teachers made was that of budgetary issues that come into play. Multilingualism is certainly an expense, and resources are always scarce and subject to alternative uses. The Malaysian government has stated that this policy advance made use of pragmatic formulas, which are based on real needs and which will ensure that a high level of quality and efficiency is maintained. The government also stressed that no language would be neglected. This is a sensitive point, as it entails deciding how to define "real needs". The teachers felt that if the "minor" languages are not used constantly, it may in the end even be hard for them to exist.

\section{The 'language garden analogy': Some recommendations}

A well known analogy among linguists between linguistic diversity and multilingualism is the 'language garden analogy' proposed by Garcia in Baker and Prys Jones (1998, p. 205). According to Garcia, it would be dull and boring to travel around the world and see that all gardens are of the same one-color flower. The variety of flowers of different shapes, sizes and colours makes our visual and aesthetic experience rich and enjoyable. Linguistic diversity also makes the world more interesting and colorful but as in the case of flowers it makes the garden more difficult to tend. Some flowers (and some languages) spread very quickly and others need extra care and protection. Multilingualism, on the other hand, requires planning and care and involves some actions such as:

- Adding flowers to the garden: Learning other languages can be an enriching experience

- Protecting rare flowers: Protecting languages at risk through legislation and education

- Nurturing flowers in danger of extinction: Intervention may be necessary and may imply positive economic discrimination

- Controlling flowers that spread quickly and naturally: Spread can be allowed if it does not kill other species.

\section{References}

Asmah Hj. Omar. (1994). "Nationism and Exoglossia: The Case of English in Malaysia", in: Abdullah Hassan 
(Eds.), Language Planning in Southeast Asia. (pp. 66- 85). Selangor: Dewan Bahasa dan Pustaka.

Asmah Hj. Omar. (2003). Language and Language Situation in South East Asia: With a Focus on Malaysia.

Kuala Lumpur: Akademi Pengajian Melayu, Universiti Malaya.

Baker, C. and Prys Jones. (1998). Encyclopedia of Bilingualism and Bilingual Education. Clevedon: Multilingual Matters.

Federal Constitution. (2000). Kuala Lumpur: International Law Book Services.

New Straits Times, (12 May 2002). Science and Maths will be in English: Panel to study its implementation.

Navrud, S. and R.C. Ready. (2002), 'Valuing culture heritage: Applying Environmental ValuationTechniques to Historic Buildings, Monuments and Artifacts'. Northhampton, MA: Edward Elgar Publishing.

Pennycook, A. (1994). Language policy as cultural politics: The double-edged sword of language education in colonial Malaya and Hong Kong. Discourse: Studies in the Cultural Politics of Education, 17 (2), 133-152.

Tollefson, J. W. (2002). Language Policies in Education: Critical Issues. London: Lawrence Erlbaum Associates. 